\title{
SPECTROSCOPIC EVALUATION OF THERMOCHROMIC PRINTED CARDBOARD BIODEGRADATION
}

\author{
Marina Vukoje (D), Rahela Kulčar (iD), Katarina Itrić (D), Mirela Rožić (iD \\ University of Zagreb, Faculty of Graphic Arts, Zagreb, Croatia
}

\begin{abstract}
Municipal solid waste, containing mostly organic fraction, paper and board, wood and textiles, continues to be a major environmental problem. In addition, paper and cardboard are the most important sources of packaging materials. Packaging waste comprising about one-third of all municipal solid waste, mainly plastic and paper based. Anaerobic degradation is one of the most environmentally friendly methods for solid organic waste treatment and widely applied for bio-energy production. In this study, the biodegradation potential of three different cardboard materials (Umca Color - UC, Propack - PP, Lux Pack $L P)$ and UV curable screen printing thermochromic ink applied on them (UV), were studied using the soil burial test under anaerobic conditions. Unprinted and printed cardboard samples were evaluated for changes over 4 months by FT-IR spectroscopy. FTIR spectra revealed the existence of $\mathrm{CaCO}_{3}$ and kaolin in cardboard coating. No significant changes occurred in the FTIR spectra of unprinted cardboard samples during biodegradation. In addition, FTIR spectra showed the presence of polyurethane acrylate in the UV thermochromic printing ink since all typical vibrational bands of polyurethane acrylate $\left(3385 \mathrm{~cm}^{-1}(\mathrm{NH}\right.$ stretching), 2955-2855 $\mathrm{cm}^{-1}$ (symmetric and asymmetric CH2 stretching), $1726 \mathrm{~cm}^{-1}$ (C=O stretching), $1365 \mathrm{~cm}^{-1}$ (C-N stretching ) and $1111 \mathrm{~cm}^{-1}\left(\mathrm{C}-\mathrm{O}-\mathrm{C}\right.$ stretching ), 810, 987 and $1408 \mathrm{~cm}^{-1}\left(\mathrm{CH}_{2}=\mathrm{CH}-\right), 1636$ $\mathrm{cm}^{-1},\left(C=C\right.$ stretching), 1064, 1195 and $1296 \mathrm{~cm}^{-1}$ (C-O stretching)) were obtained. After biodegradation of all three prints a decrease of band intensities located in the 2955-2855 $\mathrm{cm}^{-1}$ range (symmetric and asymmetric $\mathrm{CH}_{2}$ stretching), carbonyl peak around $1726 \mathrm{~cm}^{-1}$, ester linkages at $1260-1200 \mathrm{~cm}^{-1}$ and $1100-1000 \mathrm{~cm}^{-1}$ range (C-O stretching vibration) were observed. The changes in those bands may indicate the breaking down of the ester linkages, which lead to changes in polymeric structure of polymerized thermochromic ink. The highest changes in the whole spectral range were observed for the printed PP and $L P$ cardboard, mainly in the 2955-2855 cm-1 spectral range and carbonyl peak around $1720 \mathrm{~cm}^{-1}$. In addition, the changes to the dynamic colour properties of the samples were described. The highest changes in colour after biodegradation were observed for PP-UV sample, followed by UC-UV sample. This can be explained by the best absorption of ink into the cardboard structure. The studied spectroscopic methods individually are not effective methods for the evaluation of thermochromic prints changes during degradation studies, but in a combination, they can give a brief insight into the state of material.
\end{abstract}

Key words: biodegradation, cardboard, thermochromic ink, ATR - FTIR spectroscopy, colorimetric properties

\section{INTRODUCTION}

According to Holik 2013 the ratio of the worldwide consumption of the different paper and board grades has changed in the past and will continue to change in the future according to technical, economical, and social evolution and developments in the individual countries and in the world. The consumption of packaging grades have increased, graphic paper grades have stagnated, while the newsprint consumption has declined. The changes in costumers' behaviour have increased the demand for packaging materials, such as the growth in internet shopping and demand for small packaged foods (Holik, 2013). In order to fulfil consumers' expectations, packaging should be functional and attractive. Lately, intelligent packaging serves as a media for providing consumers with the necessary information about quality and safety of the packaging. Thermochromic printing inks, which can be applied on different printing substrates, can convey a message to the consumer based on the colour of the ink they are seeing.

Thermochromic printing inks are chromogenic or colour changing inks, which exhibit a colour change with exposure to different temperatures. They come in two forms: as liquid crystals or leuco dyes (Seeboth et al, 2013). Both types of thermochromic inks are usually encapsulated to enable easier handling. The sizes of microcapsules are in the range of 3 to $5 \mu \mathrm{m}$, which makes them at least ten times larger than the average pigment particle. The most widely used system for microencapsulation of thermochromic inks involves urea or melamine and formaldehyde systems, gelatine-gum arabic and epoxy resins (Fujinami, 1996). Commercially available thermochromic printing inks based on leuco dyes are consisted of microencapsulated leuco dye-developer-solvent systems and a resin binder (Seeboth et al, 2013). In 
thermochromic leuco dye-developer-solvent system thermochromic effects are based on changes of absorption caused by molecular interactions of the incorporated functional dye within its microenvironment (MacLaren et al, 2003; Seeboth et al, 2007; White et al, 1999). The thermochromic effect is caused by the formation of leuco dye-developer complexes in a reversible equilibrium redox reaction between leuco dye and developer. The reaction is triggered by interactions between the complex and the solvent during the melting or crystallization process (Seeboth et al, 2007).

Previous studies about thermochromic inks mainly investigated the chemical composition of the leuco dyes inside the microcapsules and their changes (Hajzeri et al, 2015; Panák et al, 2017; Raditoiu et al, 2016). For the commercially available thermochromic printing inks, different studies have been conducted for the purpose of their colorimetric properties and UV stability (Friškovec et al, 2013; Kulčar et al, 2011, 2010; Rožić et al, 2015). Studies dealing with biodegradability aspects showed that that polymerized ink vehicle (vegetable oil + resin) in thermochromic offset ink is more stable than the polymer resin present in UV curable screen printing thermochromic ink. SEM micrographs indicated a notably higher stability of offset ink binder and accordingly lower deformation of the microcapsules (Vukoje et al, 2018, 2017b).

The European laws require reducing the amount of all kinds of produced waste streams either by prevention, reusing or recycling (European Commission, 2008). Preventing the occurrence and reduction of waste generation is the most important step in sustainable waste management. But, if the waste is produced, than it should be recycled (by means of material or organic recycling) or used for energy production (Vukoje et al, 2018). 40\% of collected paper for recycling is wet and is not suitable for production of recycled paper but is suitable for organic recycling (Murphy et al, 2006). In addition, paper based products contaminated with food are not desirable in paper recycling facilities due to cleaning difficulties, which leads to contamination issues (Twede et al, 2015). During production of recycled paper with the classic flotation deinking process a certain types of prints may cause certain problems, for example UV curable inks due to visible speck contamination and for water based inks due to low brightness or/and pronounced colour shade.

Biodegradation of paper products is dependent upon the crystalline/amorphous ratio in cellulose, presence of lignin and different additives in paper (Van Wyk et al, 2003). Variety types of paper and cardboard are being used nowadays for different graphic products and applications, differing in their composition or coatings applied. Pinzari et al. (2010) showed that clay and aluminium could inhibit fungal development during biodegradation of paper more than $\mathrm{CaCO}_{3}$. During anaerobic biodegradation, excessive amounts of calcium can lead to precipitation of carbonate and phosphate affecting the biomass activity and buffer capacity loss while heavy metals originating from printing inks or fillers in paper can accumulate to potential toxic concentrations (Chen et al, 2008). Sridach et al, (2007) studied biodegradation of four commercial barrier coated boards (i.e., internally-sized uncoated board, one-side polyethylene coated board, double-side polyethylene coated board, and multilayer laminated board) using a soil burial test in a laboratory scale. Results showed that the base-board of four different barriercoated paperboards was found to be biodegradable in a soil environment, but the coating layer remained intact during biodegradation. Sample size and microbial population affected the rate of the biodegradation process but the directionality of the samples did not. According to Nazhad et al, (2006), the polyester-coated boards were found to be biodegradable. The fibrous component of the boards was degraded in a very short time while degradation of the coated materials of the boards was influenced by the formulation of the coating.

\section{METHODS}

\subsection{Materials}

Three different cardboard materials were used in biodegradation test. The used cardboards are representing different classes of cardboards (Table 1) according to their properties and quality.

Table 1: Cardboard classification

\begin{tabular}{lccc}
\hline Cardboard samples & Abbreviation & Grammage, $\mathbf{g} / \mathrm{m}^{2}$ & Classification \\
\hline Lux Pack & LP & 350 & GC1 \\
Propack & PP & 350 & GT2 \\
Umca Color & UC & 350 & GD2 \\
\hline
\end{tabular}


All three cardboard samples were printed with thermochromic ink in order to examine how it affects the process of biodegradation. One leuco dye based, screen-printing UV curable thermochromic ink produced by $\mathrm{CTI}^{\circledR}$ was used for printing. The thermochromic ink was coloured in purple below its activation temperature $\left(\mathrm{TA}=31^{\circ} \mathrm{C}\right)$ and changed to pink above the activation point. The biodegradation of unprinted (UC, LP, PP) and printed cardboard (UC-UV, LP-UV, PP-UV) samples was studied using the soil burial test under anaerobic conditions as it will be described in the text. Thickness of all unprinted cardboard samples was determined according to T411 standard using Enrico Toniolo DGTB001 Thickness Gauge. Print thickness values were obtained by subtracting the measured values of the thickness of unprinted paper from the measured values of thickness of paper with print. Average values of twenty measurements are presented as mean \pm SD.

\subsection{Printing}

The printing trials were carried out using the screen printing device (Siebdruckgeräte von Holzschuher K.G., Wuppertal), employing 60/64 mesh. The cardboards were printed in full tone, under the same conditions. The printed samples were dried under the UV irradiance $(30 \mathrm{~W} / \mathrm{cm})$ using Technigraf Aktiprint L 10-1 device.

\subsection{Soil burial experiments}

Soil was sieved to less than $2 \mathrm{~mm}$ particle size. Large plant materials, stones, and other inert materials were removed. Laboratory soil burial experiments were conducted at room temperature $25 \pm 3^{\circ} \mathrm{C}$ by placing the neat and printed cardboard samples horizontally in laboratory glass containers filled with soil. Samples were cut in $4 \times 5 \mathrm{~cm}$. All the samples were buried for 14, 32, 50, 80 and 120 days in glass containers filled with the soil. The water content of the soil was adjusted to $60 \%$ of its maximum water retention capacity. The commercial available reagent was used in order to allow the development of anaerobic conditions. The existence of anaerobic conditions was proved with Anaerotest (Merck) strips.

\subsection{Fourier transform infrared (FTIR) spectroscopy}

The ATR spectra of the cardboard samples, unprinted as well as printed with the ink before and after the soil burial, were measured using Shimadzu FTIR IRAffinity-21 spectrometer with the Specac Silver Gate Evolution as a single reflection ATR sampling accessory with a ZnSe flat crystal plate (index of refraction 2.4). The IR spectra were recorded in the spectral range between 4000 and $400 \mathrm{~cm}-1$ at $4 \mathrm{~cm}^{-1}$ resolution and averaged over 15 scans.

\subsection{Colorimetric Measurements}

Spectral reflectance was measured by using Ocean Optics USB2000+ spectrometer using 30mm wide integrating sphere under (8: di) measuring geometry (diffuse geometry, specular component included). The printed samples were heated/cooled on the full-cover water block (EK Water Blocks, EKWB d.o.o. Slovenia). Its temperature was varied by thermostatically controlled water block. Reflectance spectra were measured in one heating/cooling cycle by heating them from 15 to $50^{\circ} \mathrm{C}$ and then cooling them back to $15^{\circ} \mathrm{C}$. The measurements were performed in the steps of $1 \mathrm{~nm}$ for the spectral region from 400 to $750 \mathrm{~nm}$. Ocean Optics SpectraSuite software was used for the calculation of the CIELAB values from measured reflectance. The D50 illuminant and $2^{\circ}$ standard observer were applied in these calculations. Colour differences were calculated using the CIEDE2000 total colour difference formula (CIE Central Bureau, 2004).

\section{RESULTS AND DISCUSSION}

\subsection{Thickness of the samples}

Different thickness of the prints resulted from the different absorption capacity of the used cardboards and its specific surface free energy, as well as their compatibility with the used thermochromic UV ink which was studied in the previous research (Vukoje et al, 2017). 


\begin{tabular}{lcc}
\hline & Thickness, $\mathrm{mm}$ & $\begin{array}{c}\text { Increase in thickness due to UV } \\
\text { print } /(\mathrm{Im}), \mathrm{mm}\end{array}$ \\
\hline LP & $0.563 \pm 0.003$ & $0.010 \pm 0.003$ \\
LP-UV & $0.494 \pm 0.008$ & $0.003 \pm 0.007$ \\
PP & & \\
PP-UV & $0.453 \pm 0.008$ & $0.005 \pm 0.008$ \\
UC & & \\
UC-UV & & \\
\hline
\end{tabular}

\subsection{FTIR spectra of used cardboards}

Results in Figure 1 show that FTIR spectra of all unprinted cardboard materials are almost the same, indicating that the coating layer in all samples is made of the same substances.

In the fingerprint region, a broad band centred at about $1390 \mathrm{~cm}^{-1}$ is detected, followed by the peaks around 1091, 1031, 1001, 912, and $700 \mathrm{~cm}^{-1}$ indicating the presence of kaolin in the coating formulation (Grilj et al, 2012). The bands observed at 869 and $711 \mathrm{~cm}^{-1}$ (shoulder) can be attributed to the out-ofphase $\mathrm{CO}_{3}$ bending vibration and the in-plane $\mathrm{CO}_{2}$ bending vibration of calcium carbonate. Results show that for the formulation of coating, $\mathrm{CaCO} 3$ and kaolin as pigment were used. Somewhat smaller intensities and broadening of the vibrational bands on the LP samples may indicate the smaller content of the coating layer, followed by the UC sample. The sharpest vibrational bands on the PP samples may indicate the highest content of the coating on the surface.

From the Figs. 2-4 it can be seen that no significant changes occurred during biodegradation. The intensity of the kaolin and $\mathrm{CaCO}_{3}$ bands decreased mostly after 120 days of biodegradation. Only in the case of LP cardboard, the vibrational bands were weaker and poorly defined after 120 days indicating the highest rate of biodegradation and loss of coating fillers.

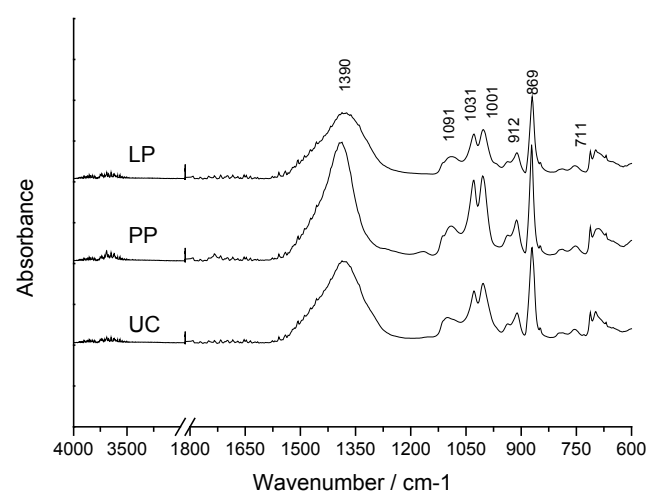

Figure 1: The ATR-FTIR spectra of unprinted cardboard samples before biodegradation test

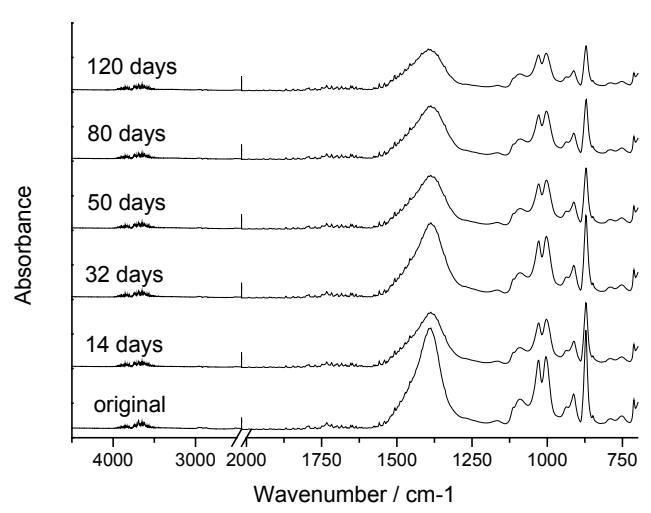

Figure 3: The ATR-FTIR spectra of unprinted PP cardboard samples before and after biodegradation test

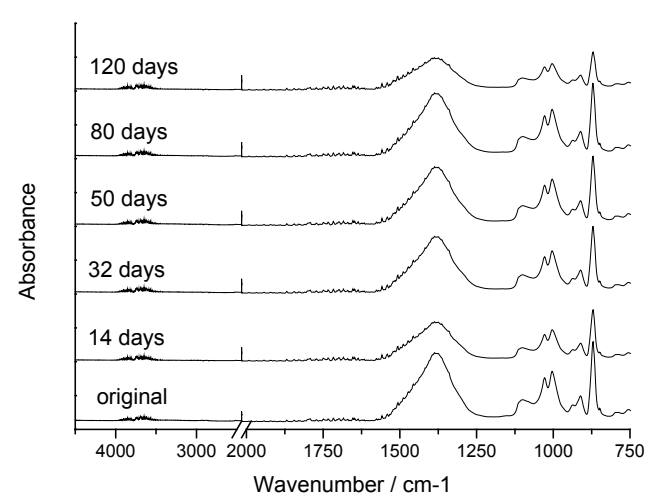

Figure 2: The ATR-FTIR spectra of unprinted UC cardboard samples before and after biodegradation test

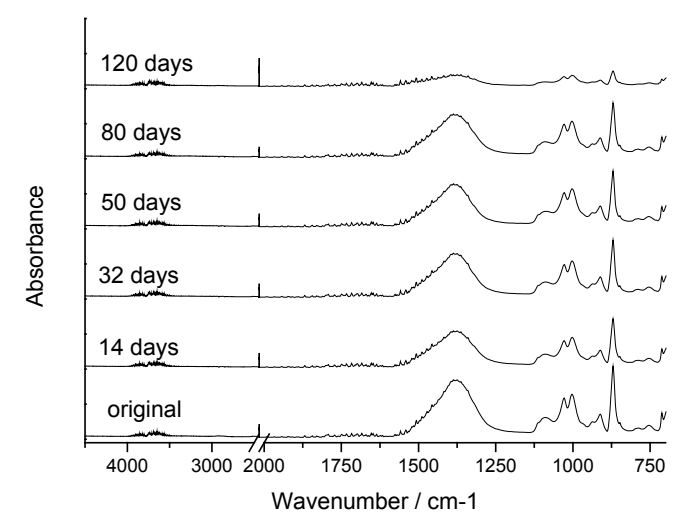

Figure 4: The ATR-FTIR spectra of unprinted LP cardboard samples before and after biodegradation test 


\subsection{FTIR spectra of thermochromic prints}

Our previous research of FTIR studies of thermochromic offset and UV curable screen printing inks showed that the observed vibrational bands most likely originated from the thermochromic ink resin and were not the result of the vibrational modes of the thermochromic composites within the microcapsules present in a significantly smaller amount. In addition, the vibrational bands of microcapsules wall material (which are present in a significantly smaller amount) which are covered with a polymer resin (present in higher amount), are probably covered and overlapped with vibrational bands of polymer resin (Vukoje et al, 2018, 2017b).

The IR spectra of the thermochromic ink (Figure 5), show all typical vibrational bands of polyurethane, such as the bands at $3385 \mathrm{~cm}^{-1}$ (NH stretching), 2955-2855 $\mathrm{cm}^{-1}$ (symmetric and asymmetric $\mathrm{CH}_{2}$ stretching), $1726 \mathrm{~cm}^{-1}$ (C=O stretching), $1462 \mathrm{~cm}^{-1}$ (ring stretching modes of phenyl moiety), $1363 \mathrm{~cm}^{-1}$ (C-N stretching) and $1111 \mathrm{~cm}^{-1}$ (C-O-C stretching) (Vukoje et al., 2018). In addition, the acrylate vibrational bands at 810, 987 and $1408 \mathrm{~cm}^{-1}$ (in-plane and out-of-plane deformation of the vinyl group $\left(\mathrm{CH}_{2}=\mathrm{CH}-\right)$ ), as well as the bands at $1636 \mathrm{~cm}^{-1}$ (double bond $(\mathrm{C}=\mathrm{C})$ stretching), vibrational bands at 1064, 1195 and $1296 \mathrm{~cm}^{-1}$ (vibrational modes of functionalities consisting of oxygen atom (C-O stretching)) were also present. The band at $1462 \mathrm{~cm}^{-1}$ could be also assigned to bending of the methylene groups present in acrylate as well, while the band at $1271 \mathrm{~cm}^{-1}$ could arise from the $\mathrm{C}-\mathrm{N}$ stretching and $\mathrm{C}-\mathrm{O}$ stretching in polyurethane and acrylate (Vukoje et al, 2018).

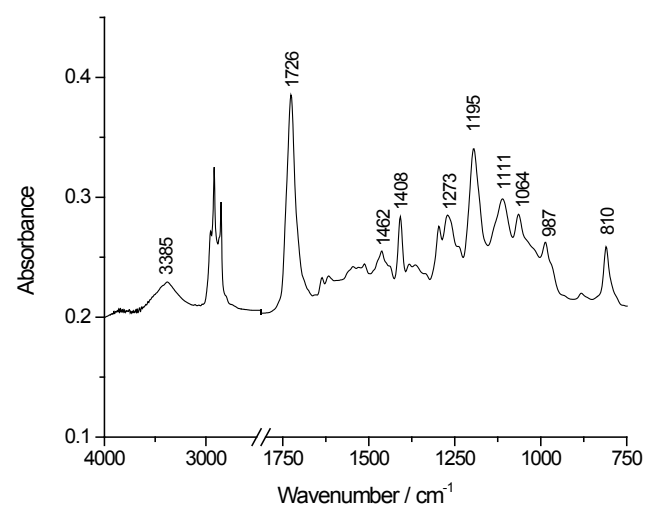

Figure 5: The ATR-FTIR spectra of UV curable thermochromic ink at $23^{\circ} \mathrm{C}$

The IR spectra, measured in attenuated total reflectance (ATR) mode, of the UV curable thermochromic prints on all samples, UC, PP and LP, were very similar for the PP-UV and UC-UV sample. Some differences can be seen for the LP-UV sample, probably due to thicker layer of ink on the cardboard surface (Fig. 6). For example, thicker layer of thermochromic ink on LP-UV sample may also be confirmed by the absence of kaolin vibrational band at $1001 \mathrm{~cm}^{-1}$ that is present in UC-UV and PP-UV sample. The band at $1001 \mathrm{~cm}^{-1}$ is not present in the thermochromic ink (Figure 5) but it can be seen in FTIR spectra of all unprinted cardboards (Figure 1). In addition, some differences can be seen in the IR spectra of thermochromic ink and obtained prints. The bands at 1408, 1294, 1192 and $1062 \mathrm{~cm}^{-1}$ in the IR spectra of the prints were weaker and poorly defined due to polymerization of polyurethane acrylate during UV curing (Vukoje et al., 2018). In the case of prints, carbonyl peak at $1726 \mathrm{~cm}^{-1}$ (in thermochromic ink) was shifted towards lower values in the case of LP-UV sample $\left(1720 \mathrm{~cm}^{-1}\right)$ and towards higher values in the case of UC-UV and PP-UV $\left(1740 \mathrm{~cm}^{-1}\right)$ after polymerization.

The IR spectra of the thermochromic UV prints on the cardboard samples before and after $14,32,50,80$ and 120 days of biodegradation are shown in Figs. 7, 8 and 9. The spectra of the prints are vertically displaced for visual clarity. After biodegradation, especially for 120 days, the changes of vibrational band intensities in the whole spectral range can be seen. A decrease of vibrational band intensities located in the $1100-1000 \mathrm{~cm}^{-1}$ range (attributed to the ester $\mathrm{C}-0$ stretching vibration), $1260-1200 \mathrm{~cm}^{-1}$ range (attributed to carbonyl oxygen linkage) and carbonyl peak around $1726 \mathrm{~cm}^{-1}$ were observed after degradation for all prints (Figs. 7, 8 and 9). These changes indicate the breaking down of the ester linkages, leading to the changes in polymeric structure. In the ranges of $1100-1000 \mathrm{~cm}^{-1}$ and $1260-1200$ $\mathrm{cm}^{-1}$, the highest changes were observed for the printed LP-UV sample, followed by print on PP-UV 
sample. In addition, the changes in the spectral range $2955-2855 \mathrm{~cm}^{-1}$ corresponding to symmetric and asymmetric $\mathrm{CH}_{2}$ stretching, were the highest in the case of LP-UV printed sample, indicating the highest change in polymeric structure, followed by PP-UV sample. A vibrational band around $1030 \mathrm{~cm}^{-1}$ was obtained in the IR spectra of the UV prints on all samples after biodegradation could be associated with silicates (Si-O stretching) adsorbed on the prints from the soil (Vukoje et al, 2018).

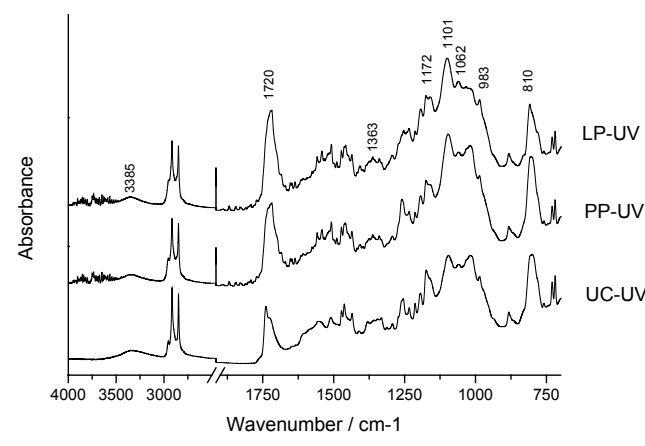

Figure 6: The ATR-FTIR spectra of printed cardboard samples before biodegradation test

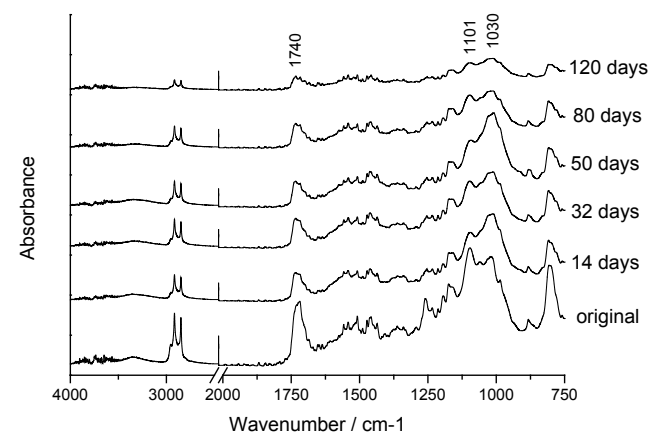

Figure 8: The ATR-FTIR spectra of printed PP-UV cardboard samples before and after biodegradation test

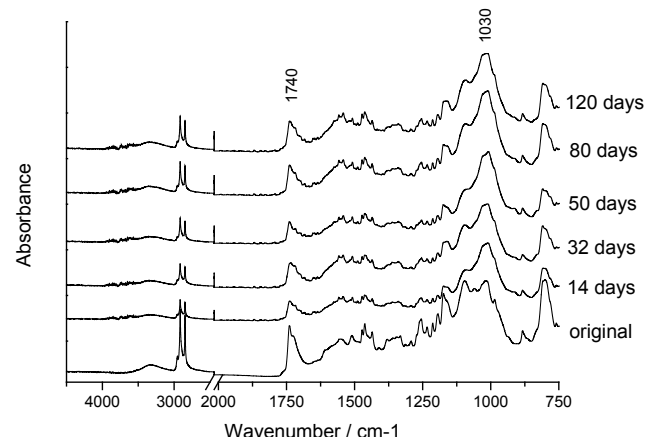

Figure 7: The ATR-FTIR spectra of printed UC-UV cardboard samples before and after biodegradation test

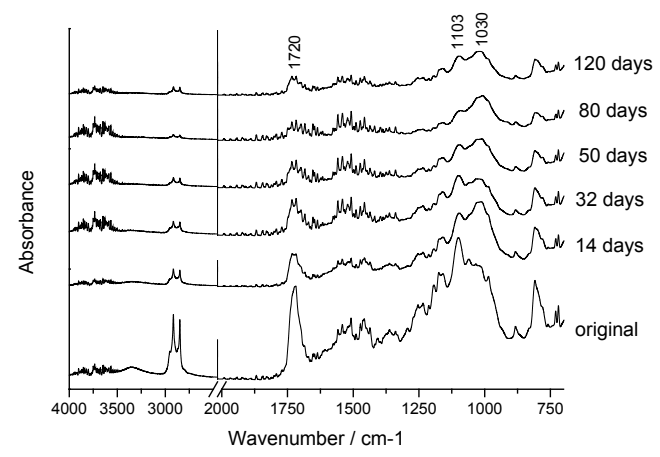

Figure 9: The ATR-FTIR spectra of printed LP-UV cardboard samples before and after biodegradation test

\subsection{Colorimetric properties of thermochromic prints}

Besides FT-IR spectroscopy, the second way of thermochromic UV curable prints biodegradability evaluation is measurement of their dynamic colorimetric properties. The reflectance spectra of thermochromic UV curable prints measured with spectrometer during heating are shown in Figure 10. Process is continuous and no abrupt change was observed. Reversible colour change is present in all samples, implying that the thermochromic effect has not been lost during biodegradation, but it was significantly reduced after 120 days of biodegradation.

Figure 11 shows colour hysteresis of prints on cardboards before and after 50 and 120 days of biodegradation. Colour hysteresis describes temperature dependence of colour for $L^{*}$ component of colour. Samples appear differently during the two reversible thermochromic reactions (change of colour from purple to pink). This is probably because by heating, the microcapsules change their shape and position, they may become larger or more on surface, so for the opposite effect of the cooling process it is necessary to invest more energy for the same effect, i.e. lower temperature are needed to bring the colour of the sample into its initial state. In addition, Figure 11 shows the influence of biodegradation after 50 and 120 days on colour hysteresis. After 50 days of biodegradation, only a slight changes occurred. The loops become smaller for all the samples, the smallest were observed for LP-UV sample, while the highest changes were observed for the PP-UV sample. However, after 120 days of biodegradation remarkable changes were observed - the TC effect is almost destroyed in PP-UV sample, whereas the resulting loop remained very small on UC-UV and LP-UV samples.

In perfectly reversible process TC sample should return to the same colour after completing the whole heating/cooling cycle and colour hysteresis of such a samples has a closed loops. The degree of reversibility of TC change can be also evaluated by the opening of hysteresis loop at low temperatures, 
i.e. by total colour difference of sample measured between heating and cooling at temperature well below the final chromic temperature (Kulčar et al, 2010).
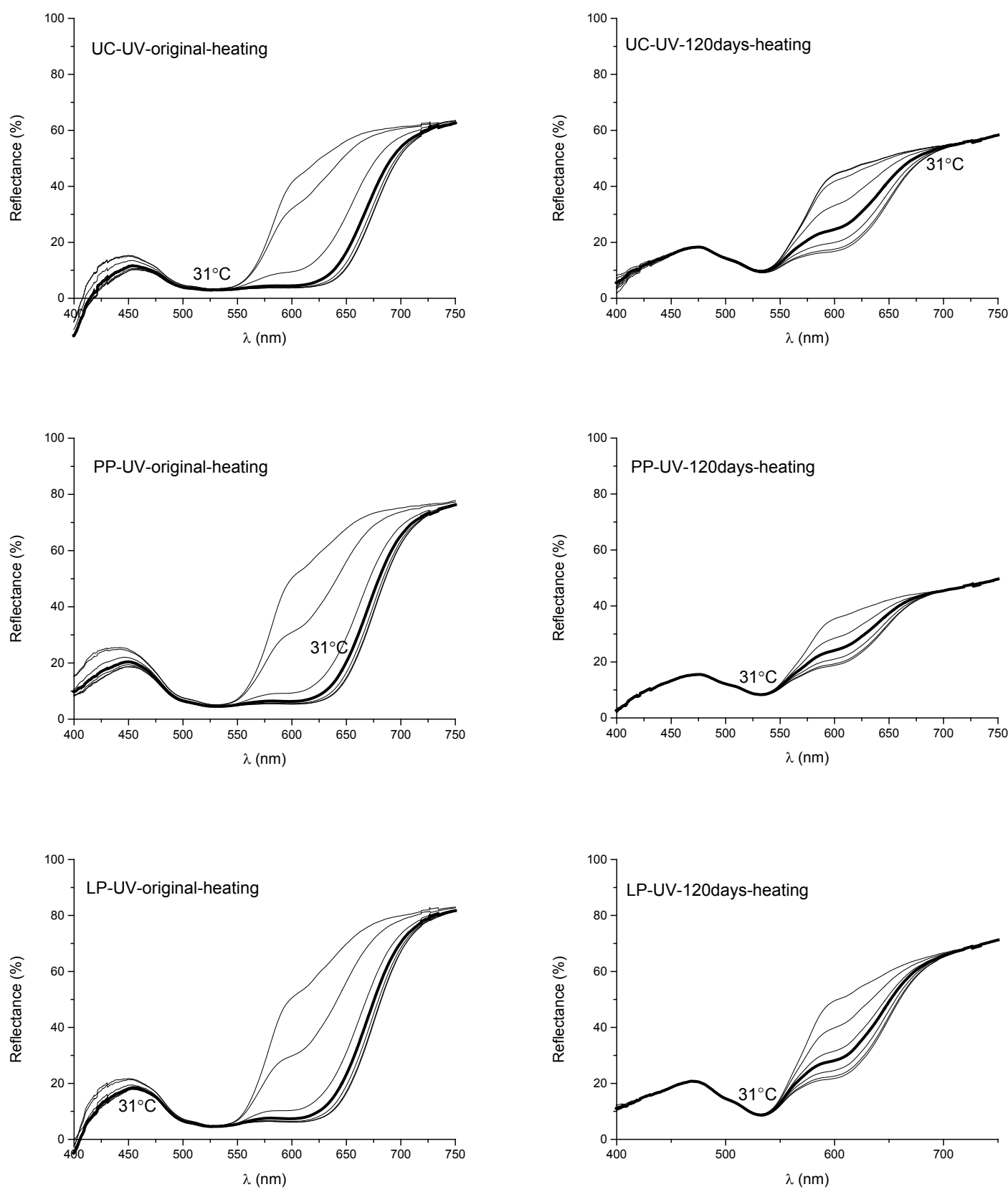

Figure 10: Reflectance spectra of printed UC-UV, PP-UV and LP-UV cardboard samples measured during heating and cooling

Results of total colour difference obtained for the original samples are given in Table 3. Results show that PP-UV sample has smallest total colour difference, followed by UC-UV sample. The highest total colour difference was obtained on LP-UV sample. This behaviour can be explained by the absorption of thermochromic ink in cardboards (Table 1). PP cardboard shows the highest absorption rate of ink into its structure (smallest increase in thickness after printing) while the LP cardboard shows almost no absorption of ink into its structure (highest increase in thickness after printing) (Table 1). In addition, in previous research the smallest surface tension beetwen thermochormik ink and cardboard was obtained in the case of PP-UV sample $\left(3.41 \mathrm{~mJ} \mathrm{~m}^{-2}\right)$ followed by UC-UV $\left(6.40 \mathrm{~mJ} \mathrm{~m}^{-2}\right)$. The highest surface tension 
was achieved in the case of LP-UV print (11.88 $\mathrm{mJ} \mathrm{m}^{-2}$ ) (Vukoje et al, 2017a). This means that the high surface tension between thermochromic ink and cardboard creates resistance and prevents the absorption of ink into the cardboard, resulting in higher total colour difference.
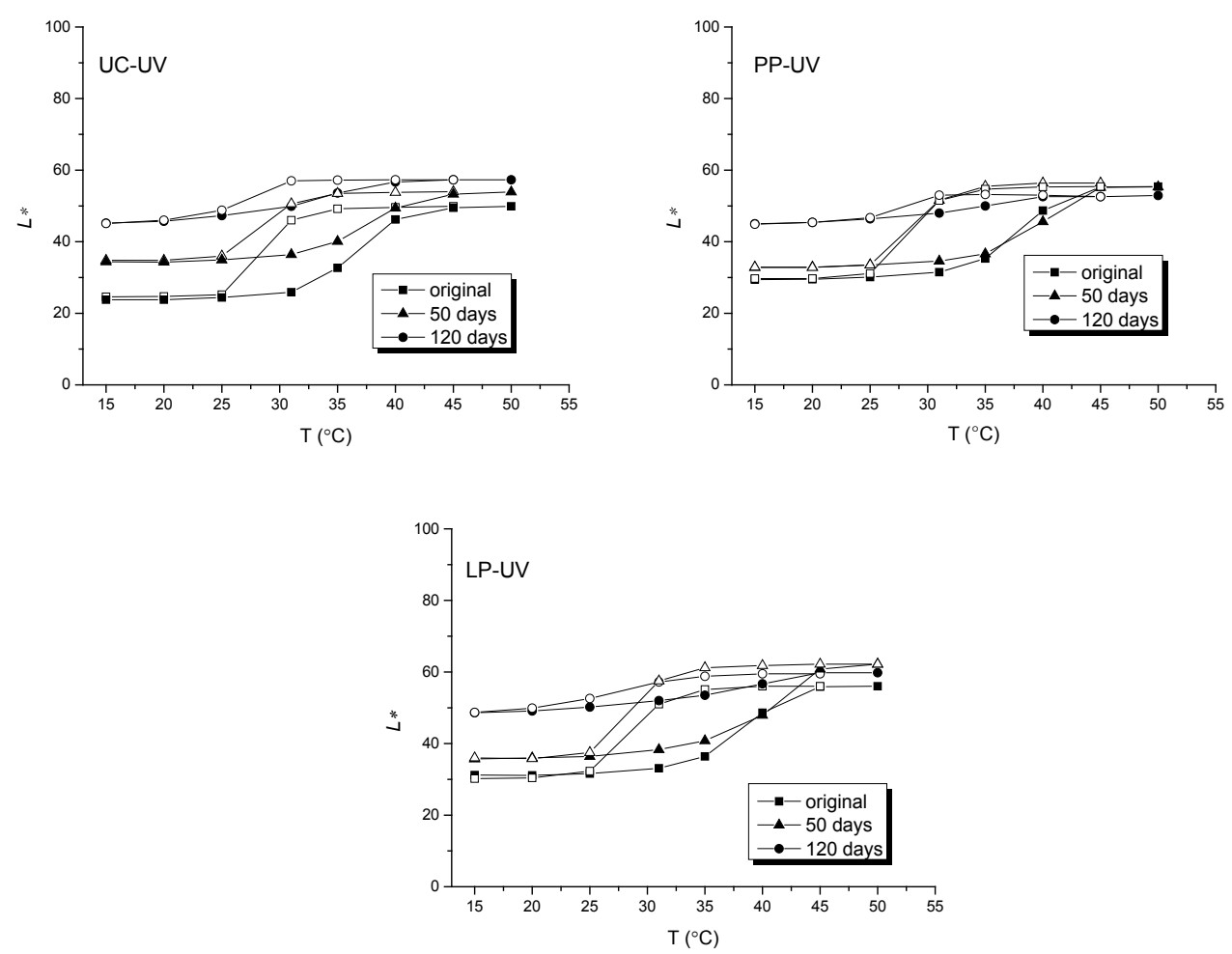

Figure 11: CIELAB lightness L* of three thermochromic UV curable prints on cardboard samples in dependence on temperature at heating (solid signs) and cooling (open signs)

In addition, the PP-UV sample which shows the highest rate of ink absorption, results in the highest colour changes after 120 days of biodegradation. This can be explained by the thickness of the ink binder that covers the microcapsules. This is in the accordance with our previous research. Microcapsules that are probably made of biodegradable melamine resin, are promoting rate of biodegradation (Vukoje et al, 2018). The print obtained on cardboard that absorbs more thermochromic ink, shows higher rate of biodegradation, since microcapsules are exposed to bacteria. If the microcapsules are covered with a thinner layer of ink polymer resin, the higher rate of biodegradation will be achieved.

Table 3: Total colour difference (CIEDE2000) between heated and cooled of the sample at $15^{\circ} \mathrm{C}$.

\begin{tabular}{ll}
\hline & CIEDE2000 \\
\hline Sample & original \\
\hline PP-UV & 0.27 \\
UC-UV & 1.49 \\
LP-UV & 2.70 \\
\hline
\end{tabular}

\section{CONCLUSION}

The studied spectroscopic methods individually are not effective methods for the evaluation of thermochromic prints changes during degradation studies, but in a combination, they can give a brief insight into the state of material. Thermochromic printing inks are functional materials with a complex structure, which provide information about a product to which it is applied. In the case of thermochromic printing inks, the studies have shown that FTIR spectroscopy mostly shows the vibrational bands of binder present in a larger amount (compared to the ratio of the microcapsules) but it does not show the changes occurring inside the microcapsules. In addition, the effect of the temperature during measurements does 
not significantly affect the spectrum change. The obtained spectrum shows the changes of the binder vibrational bands occurred during biodegradation. By colorimetric measurements, the samples are monitored in the visible part of the spectrum, in controlled temperature conditions during the heating and cooling process. Based on the resulting spectrum, it can be accurately determined when the thermochromic effect stops. In this case, FTIR spectroscopy showed the degradation of the thermocromic printing ink binder, but it doesn't show the change and degradation of the microcapsules, whereas colorimetric measurements showed the loss of thermochromic effect, pointing to the degradation of the microcapsule. However, in order to determine the overall degree of the samples biodegradation, other parameters such as weight loss during biodegradation should be considered as well. In this case, the measurements show that the greatest colour degradation is observed on the sample showing the highest absorption of thermochromic ink.

\section{ACKNOWLEDGMENTS}

The authors are grateful for the support of the University of Zagreb, Grant under the title "Modifications of conventional graphic materials with nanoparticles and chromogenic materials, and their health safety.

\section{REFERENCES}

[1] Chen, Y., Cheng, J.J., Creamer, K.S.: "Inhibition of anaerobic digestion process: A review", Bioresource Technology 99(10), 4044-4064, 2008. doi: 10.1016/j.biortech.2007.01.057.

[2] CIE Central Bureau: "Colorimetry", $3^{\text {rd }}$ ed, (CIE Central Bureau Vienna, 2004).

[3] The European Parliament and The Council Of The European Union, "Directive 2008/98/EC of the European Parliament and of the Council of 19 November 2008 on waste and repealing certain directives", Official Journal of the European Union, 51, 312/3-312/30, 2008.

[4] Friškovec, M., Kulčar, R., Klanjšek Gunde, M.: "Light fastness and high-temperature stability of thermochromic printing inks", Coloration Technology 129(3), 214-222, 2013. doi: 10.1111/cote. 12020

[5] Fujinami, F.: Patent US5500040 - Ultraviolet-curable thermochromic ink composition, 1996.

[6] Grilj, S., Klanjšek Gunde, M., Szentgyörgyvölgyi, R., Gregor-Svetec, D.: "FT-IR and UV / VIS analysis of classic and recycled papers", Papíripar 56(4), 7-13, 2012.

[7] Hajzeri, M., Bašnec, K., Bele, M., Klanjšek Gunde, M.: "Influence of developer on structural, optical and thermal properties of a benzofluoran-based thermochromic composite", Dyes and Pigments 113, 754-762, 2015. doi: 10.1016/j.dyepig.2014.10.014.

[8] Holik, H. (Ed.): "Handbook of Paper and Board", $2^{\text {nd }}$ ed, (Wiley - VCH, 2013).

[9] Kulčar, R., Friskovec, M., Hauptman, N., Vesel, A., Klanjšek Gunde, M.: "Colorimetric properties of reversible thermochromic printing inks", Dyes and Pigments 86(3), 271-277, 2010. doi: 10.1016/j.dyepig.2010.01.014.

[10] Kulčar, R., Friškovec, M., Klanjšek Gunde, M., Knešaurek, N.: “Dynamic colorimetric properties of mixed thermochromic printing inks", Coloration Technology 127(6), 411-417, 2011. doi: 10.1111/j.1478-4408.2011.00338.x.

[11] MacLaren, D.C., White, M.A.: "Dye-developer interactions in the crystal violet lactone-lauryl gallate binary system: implications for thermochromism", Journal of Materials Chemistry 13(7), 1695-1700, 2003. doi: 10.1039/b302249h.

[12] Murphy, J.D., Power, N.M.: "A Technical, Economic and Environmental Comparison of Composting and Anaerobic Digestion of Biodegradable Municipal Waste", Journal of Environmental Science and Health Part A 41(5), 865-879, 2006. doi: 10.1080/10934520600614488.

[13] Nazhad, M.M., Sridach, W., Retulainen, E., Kuusipalo, J., Parkpian, P.: "Biodegradation potential of some barrier-coated boards in different soil environments", Journal of Applied Polymer Science 100(4), 3193-3202, 2006. doi: 10.1002/app.23591.

[14] Panák, O., Držková, M., Kaplanová, M., Novak, U., Klanjšek Gunde, M.: "The relation between colour and structural changes in thermochromic systems comprising crystal violet lactone, bisphenol A, and tetradecanol", Dyes and Pigments 136, 382-389, 2017. doi: 10.1016/j.dyepig.2016.08.050 
[15] Pinzari, F., Zotti, M., De Mico, A., Calvini, P.: "Biodegradation of inorganic components in paper documents: Formation of calcium oxalate crystals as a consequence of Aspergillus terreus Thom growth", International Biodeterioration \& Biodegradation 64(6), 499-505, 2010. doi: 10.1016/j.ibiod.2010.06.001.

[16] Raditoiu, A., Raditoiu, V., Nicolae, C.A., Raduly, M.F., Amariutei, V., Wagner, L.E.: "Optical and structural dynamical behavior of Crystal Violet Lactone - Phenolphthalein binary thermochromic systems", Dyes and Pigments 134, 69-76, 2016. doi: 10.1016/j.dyepig.2016.06.046.

[17] Rožić, M., Kulčar, R., Jamnicki, S., Lozo, B., Gregor-Svetec, D.: "UV stability of thermochromic ink on paper containing clinoptilolite tuff as a filler", Cellulose Chemistry and Technology 49(7-8), 693-699, 2015.

[18] Seeboth, A., Klukowska, A., Ruhmann, R., Lötzsch, D.: "Thermochromic Polymer Materials", Chinese Journal of Polymer Science (English Edition) 25(2), 123-135, 2007. doi: 10.1142/S0256767907001923.

[19] Seeboth, A., Lotzsch, D.: "Thermochromic and thermotropic materials", (CRC Press by Taylor \& Francis Group, Boca Raton, Florida, USA, 2013).

[20] Sridach, W., Hodgson, K.T., Nazhad, M.M.: "Biodegradation and recycling potential of barrier coated paperboards", BioResources 2(2), 179-192, 2007.

[21] Twede, D., Selke, S.E., Kamdem, D.-P., Shires, D.: “Cartons, Crates and Corrugated Board, Handbook of Paper and Wood Packaging Technology", $2^{\text {nd }}$ ed, (DesTech Publications, Inc., Lancaster, Pennsylvania, USA 2015).

[22] Van Wyk, J.P.H., Mohulatsi, M.: "Biodegradation of Waste Cellulose", Journal of Polymers and the Environment 11(1), 23-28, 2003. doi: 10.1023/A:1023883428359.

[23] Vukoje, M., Miljanić, S., Hrenović, J., Rožić, M.: "Thermochromic ink-paper interactions and their role in biodegradation of UV curable prints", Cellulose 25(10), 6121-6138, 2018. doi: 10.1007/s10570-018-1970-5.

[24] Vukoje, M., Rožić, M.: "Various Valorisation Routes Of Paper Intended For Recycling - A Review", Cellulose Chemistry and Technology 52(7-8), 515-541, 2018.

[25] Vukoje, M., Rožić, M., Cigula, T.: "The role of adhesion on thermochromic printed cardboard biodegradation", ANNALS of Faculty Engineering Hunedoara - International Journal of Engineering 15, 75-82, 2017a.

[26] Vukoje, M., Rožić, M., Miljanić, S., Pasanec Preprotić, S.: "Biodegradation of thermochromic offset prints", Nordic Pulp \& Paper Research Journal 32(2), 289-298, 2017b. doi: 10.3183/npprj-2017-3202-p289-298.

[27] White, M.A., LeBlanc, M.: "Thermochromism in Commercial Products", Journal of chemical education 76(9), 1201-1205, 1999. doi: 10.1021/ed076p1201.

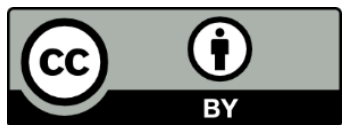

(C) 2018 Authors. Published by the University of Novi Sad, Faculty of Technical Sciences, Department of Graphic Engineering and Design. This article is an open access article distributed under the terms and conditions of the Creative Commons Attribution license 3.0 Serbia (http://creativecommons.org/licenses/by/3.0/rs/). 